\title{
Perioperative temperature management: a survey of 6 Asia-Pacific countries
}

\author{
Wenjun Koh ${ }^{1}$, Murali Chakravarthy², Edgard Simon ${ }^{3}$, Raveenthiran Rasiah ${ }^{4}$, Somrat Charuluxananan ${ }^{5}$, \\ Tae-Yop Kim ${ }^{6}$, Sophia T. H. Chew ${ }^{7}$, Anselm Bräuer ${ }^{8}$ and Lian Kah Ti ${ }^{1, *^{*}}$
}

\begin{abstract}
Background: Anesthesia leads to impairments in central and peripheral thermoregulatory responses. Inadvertent perioperative hypothermia is hence a common perioperative complication, and is associated with coagulopathy, increased surgical site infection, delayed drug metabolism, prolonged recovery, and shivering. However, surveys across the world have shown poor compliance to perioperative temperature management guidelines. Therefore, we evaluated the prevalent practices and attitudes to perioperative temperature management in the Asia-Pacific region, and determined the individual and institutional factors that lead to noncompliance.
\end{abstract}

Methods: A 40-question anonymous online questionnaire was distributed to anesthesiologists and anesthesia trainees in six countries in the Asia-Pacific (Singapore, Malaysia, Philippines, Thailand, India and South Korea). Participants were polled about their current practices in patient warming and temperature measurement across the preoperative, intraoperative and postoperative periods. Questions were also asked regarding various individual and environmental barriers to compliance.

Results: In total, 1154 valid survey responses were obtained and analyzed. 279 (24.2\%) of respondents prewarm, 508 (44.0\%) perform intraoperative active warming, and 486 (42.1\%) perform postoperative active warming in the majority of patients. Additionally, 531 (46.0\%) measure temperature preoperatively, 767 (67.5\%) measure temperature intraoperatively during general anesthesia, and 953 (82.6\%) measure temperature postoperatively in the majority of patients. The availability of active warming devices in the operating room $(p<0.001, \mathrm{OR} 10.040)$, absence of financial restriction ( $p<0.001, \mathrm{OR} 2.817$ ), presence of hospital training courses ( $p=0.011, \mathrm{OR} 1.428)$, and presence of a hospital SOP $(p<0.001$, OR 1.926) were significantly associated with compliance to intraoperative active warming.

Conclusions: Compliance to international perioperative temperature management guidelines in Asia-Pacific remains poor, especially in small hospitals. Barriers to compliance were limited temperature management equipment, lack of locally-relevant standard operating procedures and training. This may inform international guideline committees on the needs of developing countries, or spur local anesthesiology societies to publish their own national guidelines.

Keywords: Hypothermia, Temperature, Perioperative care, Monitoring, intraoperative, Practice guidelines as topic, Health knowledge, attitudes, practice, Asia

*Correspondence: anatilk@nus.edu.sg

1 Department, of Anaesthesia, National University Hospital, Singapore, Singapore

Full list of author information is available at the end of the article

\section{Background}

The past few decades have shown an increasing awareness of the physiological mechanisms and effects of temperature on perioperative morbidity and mortality [1]. Inadvertent perioperative hypothermia (IPH) original author(s) and the source, provide a link to the Creative Commons licence, and indicate if changes were made. The images or other third party material in this article are included in the article's Creative Commons licence, unless indicated otherwise in a credit line to the material. If material is not included in the article's Creative Commons licence and your intended use is not permitted by statutory regulation or exceeds the permitted use, you will need to obtain permission directly from the copyright holder. To view a copy of this licence, visit http://creativecommons.org/licenses/by/4.0/. The Creative Commons Public Domain Dedication waiver (http://creativeco mmons.org/publicdomain/zero/1.0/) applies to the data made available in this article, unless otherwise stated in a credit line to the data. 
has been defined as a core temperature of $<36{ }^{\circ} \mathrm{C}$ in the perioperative period [2].

Anesthesia leads to impairments in central and peripheral thermoregulatory responses. This is exacerbated by cool ambient operating room temperatures and exposed body cavities, resulting in inadvertent perioperative hypothermia in unwarmed surgical patients [3]. Complications include coagulopathy, increased surgical site infection, delayed drug metabolism, prolonged recovery, and shivering [4-6]. Today, temperature monitoring is the standard of care across perioperative monitoring guidelines around the world [7].

In tandem with increasing recognition, an array of options have become available for perioperative patient temperature monitoring and warming. A single layer of passive insulation only compensates for $30 \%$ of cutaneous heat losses that occur during general anesthesia, and additional layers of insulation have diminishing effectiveness [3]. Adequate temperature management requires methods of active warming, most commonly forced air warming blankets. Multiple randomized trials $[8,9]$ and systematic reviews [10-12] have shown the effectiveness of these options in maintaining normothermia, and hospitals have incorporated them into perioperative protocols [1].

Preoperatively, guidelines recommend that the patient's core temperature be measured before the start of anesthesia, and that elective surgery be postponed until the patient is normothermic [2, 13]. It is also increasingly recognized that prewarming i.e. warming of peripheral tissues before induction of anesthesia [14], is an effective technique to reduce redistributive heat loss intraoperatively, and should optimally be performed for $30 \mathrm{~min}$ preoperatively [15-17]. Intraoperatively, most guidelines advise for temperature monitoring when changes in temperature are intended, anticipated or suspected. It is typically recommended that temperature is monitored for patients undergoing general anesthesia for more than $30 \mathrm{~min}$. Guidelines also advocate routine active warming for surgical patients, especially those at higher risk $[2,13]$. Postoperatively, temperature monitoring is considered standard of care, and active warming is indicated when patients are hypothermic $[2,7,18]$.

Contrary to the growing evidence base surrounding perioperative temperature management, a wave of studies across Europe [19], Australia [20], and China [21] has consistently shown poor compliance to perioperative temperature management guidelines. This study aims to evaluate the prevalent practices and attitudes to perioperative temperature management in the Asia-Pacific region, as well as determine the individual and institutional factors that lead to noncompliance.

\section{Methods}

We conducted a cross-sectional survey on anesthesiologists and anesthesia trainees in six countries in the Asia-Pacific, namely Singapore, Malaysia, Philippines, Thailand, India and South Korea. The survey was conceived in June 2017, and the study protocol was approved by the National Healthcare Group Institutional Review Board (NHG DSRB 2017/00973) prior to study commencement. Written informed consent was waived, and return of anonymous completed questionnaires implied consent to participate. It was then progressively rolled out over an approximately one-and-a-half-year period in the six study countries. All methods were performed in accordance with the relevant guidelines and regulations.

\section{Survey administration}

A 40-question anonymous online questionnaire was developed and distributed via a shareable weblink. This weblink was disseminated to local anesthesiology societies, conferences and hospitals in the surveyed countries. All physicians practising or undergoing training in anesthesiology were invited to participate in the survey. The questionnaires were prefaced by a cover letter describing the survey, and there was no direct contact between study authors and survey participants.

A self-reported questionnaire format was chosen to maximise the outreach of the survey to cover anaesthesia practices from a wide range of settings. This was especially important as at least half of the countries surveyed had a disproportionately large proportion of small hospitals [22], which may be challenging to obtain direct audit data from. The choice of the sharable weblink was to ensure all anaesthesiologists could participate in the survey, as long as they had a valid internet connection and an email address. The authors also felt that the anonymous survey format would encourage more truthful responses as compared to a direct audit, and would hence be more representative of current practices.

To encourage participation and completion of the survey, five vehicle air purifiers were offered as lucky draw prizes for each country. Registration for the lucky draw was optional and conducted with a different form which was linked at the end of the study questionnaire. Participant information from this lucky draw was entirely separate from the study questionnaire, could not be linked back to survey responses in any way, and was not used in the study.

\section{Questionnaire development}

Creation and hosting of the online questionnaire were performed with the web-based survey tool SurveyMonkey [23]. Predominantly closed-ended questions were used, which were a combination of dichotomous, 
checkbox, multiple select and Likert-scale questions, although options for open-ended responses were provided. Phrases such as "majority of patients" were used when it was recognised that the variable of interest may not be clinically appropriate in all circumstances and patients. Attempts were made to use forced-answer questions where possible, within the limitations of the survey tool, to improve data integrity.

The questionnaire was designed to examine current practices and perceptions, as well as the limitations that may exist that prevent the use and/or adoption of best practices, best monitoring and best interventions for perioperative temperature management. Questions were based on currently published literature as well as the authors' own experiences, and was jointly constructed and reviewed by authors across the surveyed six AsiaPacific countries. The primary outcome was to determine the proportions of participants who monitor temperature perioperatively, and actively warm their patients in the preoperative, intraoperative, and postoperative phases. The secondary outcome was to determine the factors that affect compliance to perioperative temperature.

First, the participants' current practices in patient warming and temperature measurement across the preoperative, intraoperative and postoperative periods were determined. Next, participants were queried regarding the influencing factors and their personal opinions with regards to perioperative temperature management. Finally, participants were asked regarding the availability of patient warming options and temperature measuring equipment in their hospital, as well as any hospital-specific protocols or training courses. To examine the variations across individual practices or countries, additional questions were added to allow for cross-cultural comparison in the exploratory analysis.

\section{Statistical analysis}

Data analysis was conducted using SPSS 23.0 for Windows (IBM, Armonk NY, USA). Descriptive statistics were performed for survey responses and participant demographics. Univariate analyses were performed to identify correlations between demographics and primary variables, and conducted with logistic regression for categorical and ordinal variables, linear regression for continuous variables, and Kruskal-Wallis test for ranked ordinal data.

\section{Results}

A total of 1249 unique survey responses were obtained and exported from the survey software over a one-anda-half-year period between Oct 2017 to Feb 2019, representing a response rate of $14.9 \%$. Of these responses, 1154 responses $(92.4 \%)$ were valid. A proportion of questionnaires were largely empty or more than $50 \%$ incomplete $(7.6 \%)$, likely from premature closure of the webpage, and were excluded from the study via case deletion to ensure data integrity. Most respondents practised in India (32.7\%), followed by the Philippines (29.6\%), Singapore (15.2\%) and Malaysia (11.8\%). The majority of respondents were specialists $(71.6 \%)$, and practised in tertiary care hospitals (52.0\%). These hospitals range widely in terms of number of beds, number of operating theaters, and number of patients anaesthetized annually. $593(51.4 \%)$ respondents had temperature measuring equipment always available at the operating complex reception or induction room, and $783(67.9 \%)$ respondents had temperature measuring equipment always available at anesthesia recovery area. Similarly, only 521 (45.1\%) respondents had active warming devices always available at the operating complex reception or induction room, and 850 (73.7\%) respondents had active warming devices always available at the anesthesia recovery area. 624 (59.3\%) of respondents were "Often" to "Always" financially restricted in their usage of temperature management equipment. Only 210 (20.0\%) respondents' practice locations conducted training courses on the subject of perioperative temperature management, and 228 (21.7\%) had a hospital standard operating procedure (SOP) for perioperative temperature management. Demographic data of the respondents and their practice settings are further elaborated in Table 1.

Preoperatively, 531 (46.0\%) respondents measure the temperature of the majority of their patients, and 279 (24.2\%) respondents perform prewarming for the majority of their patients, and $203(17.6 \%)$ respondents perform prewarming for patients undergoing neuraxial anesthesia. During the intraoperative phase, 767 (67.5\%) of respondents measure temperature "Often" to "Always" during general anesthesia, compared to 291 (25.6\%) during neuraxial anesthesia. 508 (44.0\%) respondents perform intraoperative active warming in the majority of their patients. Postoperatively, 953 (82.6\%) of respondents measure temperature in the majority of patients, while $486(42.1 \%)$ respondents perform postoperative active warming for the majority of patients (Table 2). The respondents' compliance to key principles of perioperative temperature management guidelines are presented in Fig. 1.

On univariate analysis, the availability of active warming devices in the operating room $(p<0.001$, OR 10.040), absence of financial restriction $(p<0.001$, OR 2.817), presence of hospital training courses $(p=0.011$, OR $1.428)$, and presence of a hospital SOP $(p<0.001$, OR $1.926)$ were significantly associated with compliance to intraoperative active warming (Table 3). 
Table 1 Respondents \& practice location characteristics

\begin{tabular}{|c|c|c|c|c|c|}
\hline \multicolumn{4}{|l|}{ Characteristic } & \multirow{2}{*}{$\begin{array}{l}\text { Number } \\
377\end{array}$} & \multirow{2}{*}{$\begin{array}{l}\text { Proportion } \\
32.7 \%\end{array}$} \\
\hline \multirow[t]{6}{*}{ Country of practice } & India & & & & \\
\hline & Philippines & & & 342 & $29.6 \%$ \\
\hline & Singapore & & & 175 & $15.2 \%$ \\
\hline & Malaysia & & & 136 & $11.8 \%$ \\
\hline & Thailand & & & 91 & $7.9 \%$ \\
\hline & South Korea & & & 33 & $2.9 \%$ \\
\hline \multirow[t]{2}{*}{ Professional designation } & Trainee or fellow & & & 328 & $28.4 \%$ \\
\hline & Specialist & & & 826 & $71.6 \%$ \\
\hline \multirow[t]{4}{*}{ Hospital type } & Primary or Secondary Care & & & 93 & $8.1 \%$ \\
\hline & Tertiary Care & & & 600 & $52.0 \%$ \\
\hline & University Hospital & & & 226 & $19.6 \%$ \\
\hline & Private Hospital & & & 235 & $20.4 \%$ \\
\hline \multirow[t]{4}{*}{ Number of beds } & Less than 250 beds & & & 288 & $25.0 \%$ \\
\hline & $251-500$ beds & & & 253 & $21.9 \%$ \\
\hline & $501-1000$ beds & & & 355 & $30.8 \%$ \\
\hline & More than 1000 beds & & & 258 & $22.4 \%$ \\
\hline \multirow[t]{4}{*}{ Number of operating theaters } & Less than 5 & & & 221 & $19.2 \%$ \\
\hline & 5 to 10 & & & 325 & $28.2 \%$ \\
\hline & 11 to 20 & & & 370 & $32.1 \%$ \\
\hline & More than 20 & & & 238 & $20.6 \%$ \\
\hline \multirow[t]{4}{*}{ Number of patients anesthetized annually } & Less than 1000 & & & 145 & $12.6 \%$ \\
\hline & 1001 to 10000 & & & 495 & $42.9 \%$ \\
\hline & 10001 to 20000 & & & 286 & $24.8 \%$ \\
\hline & More than 20000 & & & 228 & $19.8 \%$ \\
\hline \multirow{3}{*}{$\begin{array}{l}\text { Locations where temperature measuring equipment is } \\
\text { always available }\end{array}$} & Theater Reception / Induction Room & & & 593 & $51.4 \%$ \\
\hline & Operating Room & & & 1050 & $91.0 \%$ \\
\hline & Anesthesia Recovery Area & & & 783 & $67.9 \%$ \\
\hline \multirow{3}{*}{$\begin{array}{l}\text { Locations where active warming devices are always avail- } \\
\text { able }\end{array}$} & Theater Reception / Induction Room & & & 521 & $45.1 \%$ \\
\hline & Operating Room & & & 979 & $84.8 \%$ \\
\hline & Anesthesia Recovery Area & & & 850 & $73.7 \%$ \\
\hline \multirow{2}{*}{$\begin{array}{l}\text { Financially restricted in temperature management equip- } \\
\text { ment }(n=1052)\end{array}$} & Never 139 & Very rarely 71 & Rarely 218 & 428 & $40.7 \%$ \\
\hline & Often 357 & Very often 128 & Always 139 & 624 & $59.3 \%$ \\
\hline \multicolumn{4}{|l|}{ Presence of hospital training courses $(n=1052)$} & 281 & $26.7 \%$ \\
\hline \multicolumn{4}{|c|}{ Presence of hospital standard operating procedure (SOP) $(n=1052)$} & 228 & $21.7 \%$ \\
\hline
\end{tabular}

$n=1154$ for all variables unless otherwise stated

When respondents were asked about their perspectives on compliance, a commonly cited barrier to effective perioperative temperature management was the lack of equipment for perioperative temperature monitoring (34.3\%), prewarming (34.2\%), intraoperative warming (31.6\%) and postoperative warming (33.5\%). 729 (63.2\%) respondents were keen for more active warming devices, and $577(50.0 \%)$ respondents were keen for more temperature measurement devices. Another area which respondents were keen for was more education for staff (73.2\%), as well as an implementation of an official hospital standard operating procedure (SOP) (65.2\%) (Table 4).
Three variables, namely the number of beds, the number of ORs, and the number of patients anesthetized annually, were used to estimate hospital size. As expected, all three variables were highly correlated, and number of ORs was chosen to as the main variable indicative of hospital size as showed the highest correlation to the other study variables.

In the exploratory analysis, it was found that countries differed significantly in terms of the number of operating theaters at the respondent's practice location $(p<0.001)$. Additionally, an increasing number of operating theaters was significantly associated with the availability of 
Table 2 Respondents' current practices on perioperative temperature management

\begin{tabular}{|c|c|c|c|c|c|}
\hline \multicolumn{4}{|l|}{ Survey question } & Number & Proportion \\
\hline \multicolumn{6}{|l|}{ Preoperative phase } \\
\hline \multicolumn{4}{|c|}{ Measure temperature preoperatively in the majority of patients } & 531 & $46.0 \%$ \\
\hline \multicolumn{4}{|l|}{ Perform prewarming in the majority of patients } & 279 & $24.2 \%$ \\
\hline \multicolumn{4}{|c|}{ Perform prewarming for patients undergoing neuraxial anesthesia } & 203 & $17.6 \%$ \\
\hline \multirow{4}{*}{ Duration of prewarming $(n=330)$} & Less than $10 \mathrm{~min}$ & & & 148 & $44.8 \%$ \\
\hline & 10 to $20 \mathrm{~min}$ & & & 125 & $37.9 \%$ \\
\hline & 21 to $30 \mathrm{~min}$ & & & 36 & $10.9 \%$ \\
\hline & More than $30 \mathrm{~min}$ & & & 21 & $6.4 \%$ \\
\hline \multicolumn{6}{|l|}{ Intraoperative phase } \\
\hline \multirow{2}{*}{$\begin{array}{l}\text { Measure temperature during general anes- } \\
\text { thesia }(n=1137)\end{array}$} & Never 43 & Very rarely 74 & Rarely 253 & 370 & $32.5 \%$ \\
\hline & Often 363 & Very often 215 & Always 189 & 767 & $67.5 \%$ \\
\hline \multirow{2}{*}{$\begin{array}{l}\text { Measure temperature during neuraxial } \\
\text { anesthesia }(n=1137)\end{array}$} & Never 242 & Very rarely 192 & Rarely 412 & 846 & $74.4 \%$ \\
\hline & Often 183 & Very often 60 & Always 48 & 291 & $25.6 \%$ \\
\hline \multirow{5}{*}{$\begin{array}{l}\text { Frequency of intraoperative temperature } \\
\text { measurement intraoperatively }(n=843)\end{array}$} & Continuously & & & 678 & $80.4 \%$ \\
\hline & Every $<5$ min & & & 23 & $2.7 \%$ \\
\hline & Every $5-10 \mathrm{~min}$ & & & 20 & $2.4 \%$ \\
\hline & Every $10-30 \mathrm{~min}$ & & & 50 & $5.9 \%$ \\
\hline & Every $>30$ min & & & 72 & $8.5 \%$ \\
\hline \multicolumn{4}{|c|}{ Perform intraoperative active warming in the majority of patients } & 508 & $44.0 \%$ \\
\hline \multirow{4}{*}{$\begin{array}{l}\text { Preferred mode(s) of intraoperative cutane- } \\
\text { ous warming (select all that apply) }(n=1017)\end{array}$} & Passive methods (e.g. Blankets) & & & 654 & $56.7 \%$ \\
\hline & Convection methods (e.g. forced air warmer) & & & 790 & $68.5 \%$ \\
\hline & Conduction methods (e.g. water mattress) & & & 296 & $25.6 \%$ \\
\hline & Radiation methods (e.g. infra-red warming device & & & 94 & $10.9 \%$ \\
\hline \multirow{4}{*}{$\begin{array}{l}\text { Average temperature in operating rooms for } \\
\text { adult surgery }\end{array}$} & Less than $21.0^{\circ} \mathrm{C}$ & & & 425 & $36.8 \%$ \\
\hline & $21.0-23.0^{\circ} \mathrm{C}$ & & & 488 & $42.3 \%$ \\
\hline & 23.1 to $24.0^{\circ} \mathrm{C}$ & & & 143 & $12.4 \%$ \\
\hline & More than $24.0^{\circ} \mathrm{C}$ & & & 98 & $8.5 \%$ \\
\hline \multicolumn{6}{|l|}{ Postoperative phase } \\
\hline \multicolumn{4}{|c|}{ Measure temperature postoperatively in the majority of patients } & 953 & $82.6 \%$ \\
\hline \multirow{5}{*}{$\begin{array}{l}\text { Frequency of intraoperative temperature } \\
\text { measurement postoperatively }(n=443)\end{array}$} & Continuously & & & 83 & $18.7 \%$ \\
\hline & Every $<5$ min & & & 18 & $4.1 \%$ \\
\hline & Every $5-10$ min & & & 32 & $7.2 \%$ \\
\hline & Every $10-30 \mathrm{~min}$ & & & 82 & $18.5 \%$ \\
\hline & Every $>30 \mathrm{~min}$ & & & 228 & $51.5 \%$ \\
\hline \multicolumn{4}{|c|}{ Perform postoperative active warming in the majority of patients } & 486 & $42.1 \%$ \\
\hline
\end{tabular}

$n=1154$ for all variables unless otherwise stated. Key perioperative temperature management principles are in bold

active warming devices $(p<0.001)$ and temperature measurement devices $(p<0.001)$ in the operating room, the absence of financial restriction $(p<0.001)$, the presence of hospital training courses $(p<0.001)$, and presence of a hospital SOP $(p=0.001)$. As the number of operating theaters in their practising location increased, the number of respondents who measure temperature preoperatively $(p=0.023)$, perform prewarming $(p<0.001)$, measure temperature during general anesthesia $(p<0.001)$, perform intraoperative active warming $(p<0.001)$, and perform postoperative active warming $(p<0.001)$ were found to significantly increase (Table 5). Exploratory analyses did not reveal correlations between primary variables and training/professional designation or hospital type.

\section{Discussion}

This is the first multinational survey of perioperative temperature management in Asia, and is particularly unique in its inclusion of a large proportion of developing countries. Importantly, a quarter of respondents were from small hospitals with less than 250 beds. A 


\section{Compliance to key principles of perioperative temperature management guidelines}

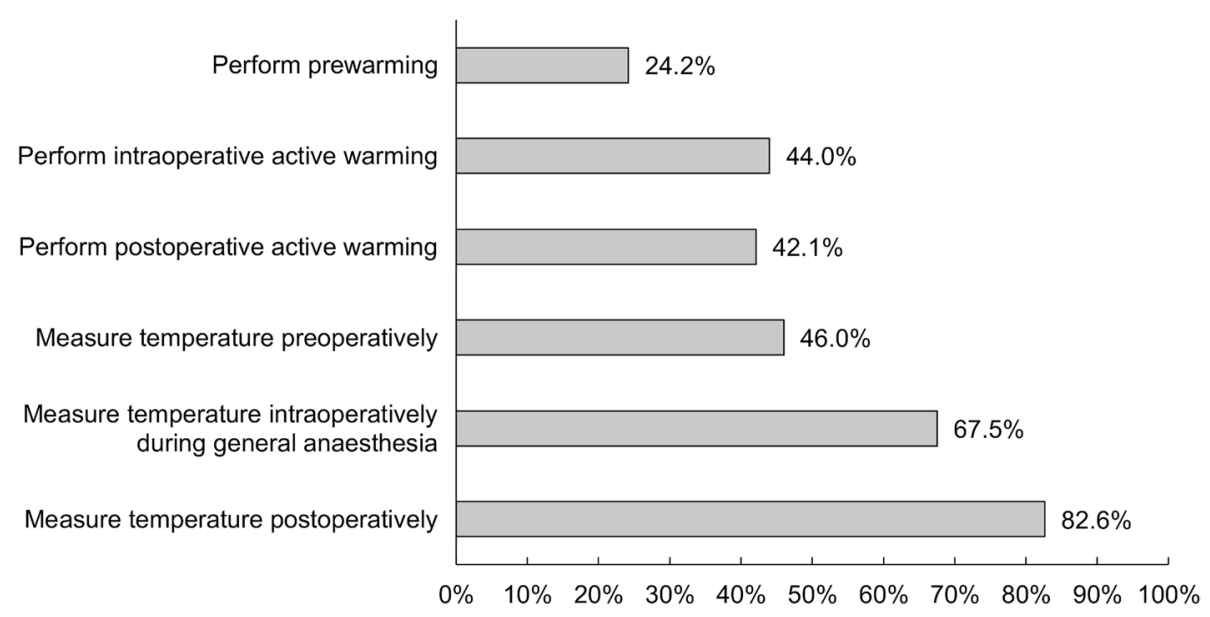

Fig. 1 Respondents' compliance to key principles of perioperative temperature management guidelines

Table 3 Factors affecting compliance to intraoperative active warming

\begin{tabular}{|c|c|c|c|c|c|c|}
\hline \multirow[t]{2}{*}{ Variable } & \multirow{2}{*}{$\begin{array}{l}\text { Perform } \\
\text { intraoperative } \\
\text { active warming }\end{array}$} & \multirow{2}{*}{$\begin{array}{l}\text { Do not perform } \\
\text { intraoperative active } \\
\text { warming }\end{array}$} & \multirow[t]{2}{*}{$p$-value } & \multirow[t]{2}{*}{ Odds ratio } & \multicolumn{2}{|c|}{$\begin{array}{l}95 \% \text { C.I. for } \\
\text { OR }\end{array}$} \\
\hline & & & & & Lower & Upper \\
\hline $\begin{array}{l}\text { Active warming devices always available for use in the } \\
\text { operating room }\end{array}$ & 492/508 (96.9\%) & $487 / 646(75.4 \%)$ & $<0.001$ & 10.040 & 5.915 & 17.041 \\
\hline $\begin{array}{l}\text { "Rarely to never" financially restricted in temperature man- } \\
\text { agement equipment }(\boldsymbol{n}=1052)\end{array}$ & $271 / 508(53.3 \%)$ & $157 / 544(28.9 \%)$ & $<0.001$ & 2.817 & 2.183 & 3.636 \\
\hline Presence of hospital training courses $(n=1052)$ & $154 / 508(30.3 \%)$ & $127 / 544(23.3 \%)$ & 0.011 & 1.428 & 1.086 & 1.879 \\
\hline $\begin{array}{l}\text { Presence of hospital standard operating procedure (SOP) } \\
(\mathbf{n = 1 0 5 2 )}\end{array}$ & 139/508 (27.4\%) & $89 / 544(16.4 \%)$ & $<0.001$ & 1.926 & 1.427 & 2.598 \\
\hline
\end{tabular}

$n=1154$ for all variables unless otherwise stated

number of international guidelines have been published to reduce inadvertent perioperative hypothermia, largely by national societies based in developed countries [2, 7, 13, 24-29]. None of the studied countries have national guidelines to reduce perioperative hypothermia.

Nevertheless, compliance rates to international perioperative temperature management guidelines across countries and institutions are generally poor [30,31]. This survey similarly found a poor compliance rate to perioperative temperature management guidelines among respondents. Less than half of respondents (44.0\%) perform intraoperative active warming for the majority of their patients. Additionally, less than a quarter of respondents $(24.2 \%)$ prewarm the majority of their patients. Even when active warming or temperature monitoring is carried out, most respondents do not follow best practices laid out by international guidelines.
The greatest barrier to compliance appears to be the availability of equipment for perioperative temperature management in all three perioperative phases. A substantial proportion of survey respondents do not have ready access to temperature measuring equipment and active warming devices at critical locations, namely the operating complex reception / induction room, the operating theater, and the anesthesia recovery area. Having active warming equipment readily available in the operating room was associated with ten times the odds of performing intraoperative active warming.

Often, the lack of resources is due to financial constraints, which many respondents face. Respondents with financial constraints were about a third as likely to perform intraoperative warming. The association between lack of equipment and noncompliance has also been noted in another national study on perioperative temperature management [32]. It must be emphasized that 
Table 4 Respondents' perspectives on perioperative temperature management

\begin{tabular}{|c|c|c|}
\hline Survey question & Number & Proportion \\
\hline \multicolumn{3}{|l|}{ Perioperative temperature monitoring } \\
\hline I don't believe perioperative temperature monitoring is necessary for the majority of cases & 82 & $7.1 \%$ \\
\hline I am limited by the availability of equipment for perioperative temperature monitoring & 396 & $34.3 \%$ \\
\hline \multicolumn{3}{|l|}{ Prewarming } \\
\hline I do not believe prewarming is necessary for the majority of cases & 131 & $11.4 \%$ \\
\hline I am limited by the availability of equipment for prewarming & 395 & $34.2 \%$ \\
\hline There is not enough time to do prewarming & 364 & $31.5 \%$ \\
\hline \multicolumn{3}{|l|}{ Intraoperative warming } \\
\hline I do not believe intraoperative warming is necessary for the majority of the cases & 15 & $1.3 \%$ \\
\hline I am limited by the availability of active warming equipment & 365 & $31.6 \%$ \\
\hline I think active warming is not practical as it competes with surgical access & 43 & $3.7 \%$ \\
\hline I think that forced air warmers may increase infection risk by blowing bacteria into the surgical wound & 61 & $5.3 \%$ \\
\hline \multicolumn{3}{|l|}{ Postoperative warming } \\
\hline I don't believe postoperative warming is necessary for the majority of the cases & 27 & $2.3 \%$ \\
\hline I am limited by the availability of equipment for postoperative warming & 387 & $33.5 \%$ \\
\hline \multicolumn{3}{|l|}{ Areas that can be improved in the monitoring and prevention of perioperative hypothermia } \\
\hline More temperature measurement devices & 577 & $50.0 \%$ \\
\hline Better temperature measurement devices & 483 & $41.9 \%$ \\
\hline More active warming devices & 729 & $63.2 \%$ \\
\hline Better active warming devices & 542 & $47.0 \%$ \\
\hline More education (materials, training) for staff & 845 & $73.2 \%$ \\
\hline Renewing outdated educational materials & 374 & $32.4 \%$ \\
\hline Implementation of an official hospital SOP & 752 & $65.2 \%$ \\
\hline Better enforcement of existing hospital SOP & 393 & $34.1 \%$ \\
\hline
\end{tabular}

$n=1154$ for all variables unless otherwise stated. Question headings are in bold

Table 5 Primary variables and participant characteristics grouped by number of operating theaters

\begin{tabular}{|c|c|c|c|c|c|c|c|c|}
\hline \multirow[t]{2}{*}{ Variable } & \multicolumn{4}{|c|}{ Number of operating theaters } & \multirow[t]{2}{*}{$p$-value } & \multirow[t]{2}{*}{ Odds ratio } & \multicolumn{2}{|c|}{$\begin{array}{l}95 \% \text { C.I. for } \\
\text { OR }\end{array}$} \\
\hline & $<5$ & $5-10$ & $11-20$ & $>20$ & & & Lower & Upper \\
\hline \multicolumn{9}{|l|}{ Primary variables } \\
\hline Measure temperature preoperatively & $90(40.7 \%)$ & $142(43.7 \%)$ & $181(48.9 \%)$ & $118(49.6 \%)$ & 0.023 & 1.141 & 1.018 & 1.279 \\
\hline Perform prewarming & $38(17.2 \%)$ & $62(19.1 \%)$ & $113(30.5 \%)$ & $66(27.7 \%)$ & $<0.001$ & 1.293 & 1.130 & 1.480 \\
\hline $\begin{array}{l}\text { Measure temperature intraoperatively during gen- } \\
\text { eral anesthesia }(\boldsymbol{n = 1 1 3 7 )}\end{array}$ & $94(43.7 \%)$ & $174(54.4 \%)$ & $303(82.6 \%)$ & $196(83.4 \%)$ & $<0.001$ & 2.130 & 1.856 & 2.444 \\
\hline Perform intraoperative active warming & $58(26.2 \%)$ & $122(37.5 \%)$ & $197(53.2 \%)$ & $131(55.0 \%)$ & $<0.001$ & 1.550 & 1.375 & 1.746 \\
\hline Measure temperature postoperatively & $194(87.8 \%)$ & $255(78.5 \%)$ & $295(79.7 \%)$ & $209(87.8 \%)$ & 0.828 & 1.017 & 0.876 & 1.180 \\
\hline Perform postoperative active warming & $70(31.7 \%)$ & $135(42.5 \%)$ & $181(48.9 \%)$ & $100(42.0 \%)$ & 0.005 & 1.178 & 1.012 & 1.370 \\
\hline \multicolumn{9}{|l|}{ Participant characteristics } \\
\hline $\begin{array}{l}\text { Active warming devices always available for use in } \\
\text { the operating room }\end{array}$ & $147(66.5 \%)$ & $269(82.8 \%)$ & $348(94.1 \%)$ & $215(90.3 \%)$ & $<0.001$ & 1.999 & 1.679 & 2.380 \\
\hline $\begin{array}{l}\text { Temperature measurement devices always available } \\
\text { for use in the operating room }\end{array}$ & $184(83.3 \%)$ & $294(90.5 \%)$ & $351(94.9 \%)$ & $221(92.9 \%)$ & $<0.001$ & 1.516 & 1.236 & 1.860 \\
\hline $\begin{array}{l}\text { "Rarely to never" financially restricted in temperature } \\
\text { management equipment }(n=1052)\end{array}$ & $184(83.3 \%)$ & $294(90.5 \%)$ & $351(94.9 \%)$ & $221(92.9 \%)$ & $<0.001$ & 1.337 & 1.180 & 1.515 \\
\hline Presence of hospital training courses $(n=1052)$ & $30(16.3 \%)$ & $64(22.3 \%)$ & $110(31.1 \%)$ & $77(33.9 \%)$ & $<0.001$ & 1.389 & 1.208 & 1.598 \\
\hline $\begin{array}{l}\text { Presence of hospital standard operating procedure } \\
\text { (SOP) }(n=1052)\end{array}$ & $23(12.5 \%)$ & $59(20.6 \%)$ & $88(24.9 \%)$ & $58(25.6 \%)$ & 0.001 & 1.292 & 1.113 & 1.499 \\
\hline
\end{tabular}

$n=1154$ for all variables unless otherwise stated 
compliance to guidelines leads to a reduction in perioperative hypothermia and associated adverse events, which can result in net cost savings from fewer complications and a shorter hospital stay $[8,9]$. This has been examined in cost analysis reports in the UK [33] and Australia [34].

In the face of significant resource constraints, it can be exceedingly difficult for full compliance to best practices. These guidelines need to be contextualized to the local hospital setting and available resources, such as through hospital training courses or SOPs, to be truly effective. As seen from their survey responses, most respondents already believe in the key tenets of perioperative temperature management guidelines, but are still keen for more training and hospital SOPs on perioperative temperature management. Additionally, respondents in hospitals with training courses or SOPs were 42 and $92 \%$ more likely to be compliant to intraoperative active warming respectively. Systematic changes to hospital SOPs have been shown to improve compliance to guidelines and translate into improved clinical outcomes [35-38]. Ideally, various stakeholders in hospital management as well as local experts need to be involved for the conceptualization of the most optimal local strategy, and this can be disseminated into individual hospital training courses or SOPs.

For instance, more than a third of respondents have a cold average operating room temperature of less than $21.0^{\circ} \mathrm{C}$. Raising ambient room temperatures in the induction room and operating theaters can alleviate cutaneous heat losses [39-42]. While this is no replacement for active warming devices, in situations when active warming devices need to be rationed, this can reduce the risk of inadvertent intraoperative hypothermia.

As others have found before [43], it appears that the smaller hospitals face more constraints implementing best practices. Additionally, smaller hospitals also have greater difficulties in terms of resource constraints, and have fewer hospital training courses and hospital SOPs. Having these institutional support mechanisms may be important to improving temperature measurement and patient warming rates in these practice settings. Unfortunately, smaller hospitals also often account for a disproportionately large proportion of patients treated, and this especially true in at least 3 of the 6 countries surveyed [22]. Furthermore, the countries surveyed also tended to have significantly different hospital sizes, which may account for cross-cultural differences in compliance. As these hospitals have the greatest potential for improvement, they should not be neglected in national guidelines and policy-making.

Another significant observation was that compliance rates to intraoperative temperature monitoring during neuraxial anesthesia was half that of general anesthesia $(25.6 \%$ vs $67.5 \%)$, despite the fact that neuraxial anesthesia also impairs thermoregulatory mechanisms to a similar degree as general anesthesia [3]. The importance of intraoperative warming even in patients undergoing neuraxial anesthesia should be further emphasized in subsequent iterations of perioperative temperature management guidelines.

Only a small proportion of respondents feel that active warming is intraoperative warming is unnecessary, or that forced air warming can increase infection risk or interfere with surgical access. While these were traditionally thought to be important barriers to intraoperative active warming, these factors appear to be less important to the study participants, and other factors (eg. resource constraints, training and SOPs) may be more critical.

The focus of this study was to provide a broad overview of perioperative temperature management practices in a wide variety of practice locations. However, as this study was based on self-reported data, there are inherent reporting and recall biases. The study had a relatively limited response rate of $14.9 \%$, which is similar to other published surveys of physicians using a weblink-only survey methodology [44]. Additionally, over $92 \%$ of the respondents completed the survey, attesting to the accuracy of the information.

If present, the important sources of response bias would be from respondents who are (1) unable to complete the survey, such as those in low-resource locations without internet access, or (2) are not keen to complete the survey, such as those who do not value perioperative temperature management as important to patient outcomes. These respondents will be under-represented the study. Such biases would be expected to artificially inflate compliance rates, although this was not observed in the study results. Nonetheless, the results of this study should be verified by local audits where possible, ideally in tandem with changes to institutional policies, followed by efforts to close the audit loop.

\section{Conclusions}

In conclusion, this survey found that compliance to perioperative temperature management guidelines is generally poor, especially among smaller hospitals. Environmental/resource limitations is the single largest contributor to noncompliance in the study population as it is a key enabler in effective perioperative temperature management. From an institutional perspective, other areas that are likely to improve compliance rates would be more training on perioperative temperature management, and the development of a hospital SOP. These findings may inform international guideline committees on the needs of developing countries, or may spur local anesthesiology societies to publish their own guidelines specific to the local context. 


\section{Supplementary Information}

The online version contains supplementary material available at https://doi. org/10.1186/s12871-021-01414-6.

Additional file 1. Asia-Pacific Perioperative Temperature Management Questionnaire. Questionnaire used for data collection.

\section{Acknowledgements}

The authors wish to thank the anesthesiologists who participated in the survey, and acknowledge 3M (Singapore) for their support.

\section{Authors' contributions}

WK was involved in data curation, formal analysis, and writing the manuscript draft. MC was involved in conceptualisation, funding acquisition, investigation, methodology, and resources. ES was involved in conceptualisation, funding acquisition, investigation, methodology, and resources. RR was involved in conceptualisation, funding acquisition, investigation, methodology, and resources. SC was involved in conceptualisation, funding acquisition, investigation, methodology, and resources. TYK was involved in conceptualisation, funding acquisition, investigation, methodology, and resources. STHC was involved in conceptualisation, data curation, formal analysis, funding acquisition, investigation, methodology, resources, and writing the manuscript draft. AB was involved in conceptualisation, funding acquisition, investigation, methodology, and resources. LKT was involved in conceptualisation, data curation, formal analysis, funding acquisition, investigation, methodology, project administration, software, resources, supervision, and writing the manuscript draft. The author(s) read and approved the final manuscript.

\section{Funding}

The license fee for the online questionnaire (SurveyMonkey ${ }^{\circledR}$, San Mateo, CA USA) was provided by the Department of Anaesthesia, National University Health System Singapore, awarded to LKT. The lucky draw prizes for survey respondents were provided by $3 \mathrm{M}$ (Saint Paul, MN, USA. https://www.3m. $\mathrm{com} /$ ). The funders had no role in the design of the study, and collection, analysis, and interpretation of data, and in writing the manuscript.

\section{Availability of data and materials}

The datasets generated and/or analysed during the current study are available in the National University of Singapore Library Database, (URL: https://doi.org/ 10.25540/8MFS-TT7D).

\section{Declarations}

\section{Ethics approval and consent to participate}

The study protocol was approved by the National Healthcare Group Institutional Review Board (NHG DSRB 2017/00973) prior to study commencement. The questionnaire was anonymous, with no identifiable data was collected on participants. Written informed consent was waived, and return of anonymous completed questionnaires implied consent to participate. All methods were performed in accordance with the relevant guidelines and regulations.

\section{Consent for publication}

Not applicable.

\section{Competing interests}

The authors of this manuscript have the following competing interests: $A B$ is a member of the advisory board of $3 \mathrm{M}$ Europe, and has received payments from 3 M Germany, 3 M Europe, 3 M Asia Pacific Pte Ltd. (https://www.3m. $\mathrm{com} /$ ) for consultancy work. MC, ES, RR, SC, TYK, and LKT are Members of the Asia Normothermia Advisory Board. WK and STHC declare no competing interests. A total of 848 participants participated in the $3 \mathrm{M}$ lucky draw, and the lucky draw prizes for survey respondents were provided by 3 M (Saint Paul, MN, USA. https://www.3m.com/). The lucky prizes were distributed independently of the study. The license fee for the online questionnaire (SurveyMonkey ${ }^{\circledR}$, San Mateo, CA, USA) was provided by the Department of Anaesthesia, National University Hospital, Singapore, awarded to LKT.

\section{Author details}

'Department, of Anaesthesia, National University Hospital, Singapore, Singapore. ${ }^{2}$ Department of Anesthesia, Critical Care and Pain Relief, Fortis Hospital, Bangalore, Karnataka, India. ${ }^{3}$ Department of Anesthesiology, Philippine General Hospital, University of the Philippines, Ermita, Manila, Philippines. ${ }^{4}$ Department of Anesthesiology, Avisena Specialist Hospital, Shah Alam, Selangor, Malaysia. ${ }^{5}$ Department of Anesthesiology, Faculty of Medicine, Chulalongkorn University, Pathumwan, Bangkok, Thailand. ${ }^{6}$ Department of Anesthesiology, Konkuk University Medical Center, Gwangjin-gu, Seoul, Republic of Korea. ${ }^{7}$ Department of Anaesthesia, Singapore General Hospital, Singapore, Singapore. ${ }^{8}$ Department of Anesthesiology, University Hospital Goettingen, Goettingen, Germany. ${ }^{9}$ Department of Anaesthesia, Yong Loo Lin School of Medicine, National University of Singapore, Singapore, Singapore.

Received: 17 January 2021 Accepted: 17 June 2021

Published online: 16 August 2021

\section{References}

1. Hopf HW. Perioperative temperature management: time for a new standard of care? Anesthesiology. 2015;122:229-30.

2. National Institute for Health and Care Excellence (NICE). Hypothermia: prevention and management in adults having surgery. NICE Clinical Guideline CG65. 2016. https://www.nice.org.uk/guidance/cg65. Accessed 5 Oct 2019.

3. Sessler DI. Perioperative thermoregulation and heat balance. Lancet. 2016;387:2655-64.

4. Reynolds L, Beckmann J, Kurz A. Perioperative complications of hypothermia. Best Pract Res Clin Anaesthesiol. 2008;22:645-57.

5. Hannenberg AA, Sessler DI. Improving perioperative temperature management. Anesth Analg. 2008;107:1454-7.

6. Ruetzler K, Kurz A. Consequences of perioperative hypothermia. Handb Clin Neurol. 2018;157:687-97.

7. American Society of Anesthesiologists (ASA). Standards for basic anesthetic monitoring. Committee of origin: standards and practice parameters. 2016. https://www.asahq.org/standards-and-guidelines/ standards-for-basic-anesthetic-monitoring. Accessed 8 Aug 2019.

8. Andrzejowski J, Hoyle J, Eapen G, Turnbull D. Effect of prewarming on post-induction core temperature and the incidence of inadvertent perioperative hypothermia in patients undergoing general anaesthesia. Br J Anaesth. 2008;101:627-31.

9. Frank SM, Fleisher LE, Breslow MJ, Hiaains MS, Ollson KF, Kelly S, et al. Perioperative maintenance of normothermia reduces the incidence of morbid cardiac events: a randomized clinical trial. JAMA. 1997;277:1127-34.

10. Madrid E, Urrútia G, RoquéiFiguls M, Pardo-Hernandez H, Campos JM, Paniagua P, et al. Active body surface warming systems for preventing complications caused by inadvertent perioperative hypothermia in adults. Cochrane Database Syst Rev. 2016;2016:CD009016.

11. Moola S, Lockwood C. Effectiveness of strategies for the management and/or prevention of hypothermia within the adult perioperative environment. Int J Evid Based Healthc. 2011;9:337-45.

12. Campbell G, Alderson P, Smith AF, Warttig S. Warming of intravenous and irrigation fluids for preventing inadvertent perioperative hypothermia. Cochrane Database Syst Rev. 2015;2015:CD009891.

13. Torossian A, Bräuer A, Höcker J, Bein B, Wulf H, Horn EP. Preventing inadvertent perioperative hypothermia. Dtsch Arztebl Int. 2015;112:166-72.

14. Matsukawa T, Sessler DI, Sessler AM, Schroeder M, Ozaki M, Kurz A, et al. Heat flow and distribution during induction of general anesthesia. Anesthesiology. 1995;82:662-73.

15. Connelly L, Cramer E, DeMott Q, Piperno J, Coyne B, Winfield C, et al. The optimal time and method for surgical prewarming: a comprehensive review of the literature. J PeriAnesthesia Nurs. 2017;32:199-209. https:// doi.org/10.1016/j.jopan.2015.11.010.

16. Sessler DI, Schroeder M, Merrifield B, Matsukawa T, Cheng C. Optimal duration and temperature of prewarming. Anesthesiology. 1995;82:674-81.

17. Bräuer A, Waeschle RM, Heise D, Perl T, Hinz J, Quintel M, et al. Preoperative prewarming as a routine measure. First experiences. Anaesthesist. 2010;59:842-50. https://doi.org/10.1007/s00101-010-1772-0. 
18. Whitaker DK, Booth H, Clyburn P, Harrop-Griffiths W, Hosie H, Kilvington $B$, et al. Guidelines: immediate post-anaesthesia recovery. Anaesthesia. 2013;68:288-97.

19. Torossian A. Survey on intraoperative temperature management in Europe. Eur J Anaesthesiol. 2007;24:668-75. https://doi.org/10.1017/ S0265021507000191.

20. Duff J, Walker K, Edward K-L. Incidence of perioperative inadvertent hypothermia and compliance with evidence-based recommendations at four Australian hospitals: a retrospective chart audit. ACORN J Perioper Nurs Aust. 2014;27:16-23.

21. Yi J, Xiang Z, Deng X, Fan T, Fu R, Geng W, et al. Incidence of inadvertent intraoperative hypothermia and its risk factors in patients undergoing general anesthesia in Beijing: a prospective regional survey. PLoS One. 2015;10:e0136136.

22. Arunanondchai J, Fink C. Trade in health services in the ASEAN region. Policy research working paper; no. 4147. World Bank. 2007. https://openk nowledge.worldbank.org/handle/10986/7165.

23. Finley R. SurveyMonkey. Portland, OR. 1999. https://www.surveymonkey. com/. Accessed 4 Apr 2017.

24. Checketts MR. AAGBI recommendations for standards of monitoring during anaesthesia and recovery 2015. Anaesthesia. 2016;71:85-93. https:// doi.org/10.1111/anae.13421.

25. European Board of Anaesthesiology (EBA). Recommendations for minimal monitoring during anaesthesia and recovery. 1-5. http://www. eba-uems.eu/resources/PDFS/safety-guidelines/EBA-Minimal-monitor. pdf. Accessed 15 Feb 2020.

26. Dobson G, Chow L, Flexman A, Hurdle H, Kurrek M, Laflamme C, et al. Canadian anesthesiologists' society guidelines to the practice of anesthesia - revised edition 2019. Can J Anesth. 2019;66:75-108. https://doi.org/ 10.1007/s12630-018-1248-2

27. Australian and New Zealand College of Anaesthetists (ANZCA). Guidelines on monitoring during anaesthesia. 2017;:4-8. http://www.anzca. edu.au/documents/ps18-2015-guidelines-on-monitoring-during-anaes the.pdf. Accessed 15 Feb 2020.

28. Gelb AW, Morriss WW, Johnson W, Merry AF. World Health OrganizationWorld Federation of Societies of Anaesthesiologists (WHO-WFSA) international standards for a safe practice of anesthesia. Anesth Analg. 2018;126:2047-55. https://doi.org/10.1213/ANE.0000000000002927.

29. Hooper VD, Chard R, Clifford T, Fetzer S, Fossum S, Godden B, et al. ASPAN's evidence-based clinical practice guideline for the promotion of perioperative normothermia. J PeriAnesthesia Nurs. 2009;24:271-87.

30. Bindu B, Bindra A, Rath G. Temperature management under general anesthesia: compulsion or option. J Anaesthesiol Clin Pharmacol. 2017;33:306. https://doi.org/10.4103/joacp.JOACP_334_16.

31. Harper CM, Andrzejowski JC, Alexander R. NICE and warm. Br J Anaesth. 2008;101:293-5. https://doi.org/10.1093/bja/aen233.

32. Ahmet Y, Gamze T, Cigdem UK, Cevdet Y. Perioperative temperature monitoring in general and neuraxial anesthesia: a survey study. AinShams J Anesthesiol. 2020;12:1-6.
33. National Institute for Health and Care Excellence (NICE). Resource impact report: hypothermia: prevention and management in people having surgery (CG65). 2016. https://www.nice.org.uk/guidance/cg65/resources/ resource-impact-report-pdf-2731292749.

34. Ralph N, Gow J, Conway A, Duff J, Edward KL, Alexander K, et al. Costs of inadvertent perioperative hypothermia in Australia: a cost-of-illness study. Collegian. 2020;27:345-51.

35. Gallagher GA, McLintock T, Booth MG. Closing the audit loop-prevention of perioperative hypothermia: audit and reaudit of perioperative hypothermia. Eur J Anaesthesiol. 2003;20:750-2. https://doi.org/10.1017/S0265 021503001224

36. Jeganathan V. Completing the audit cycle and beyond: perioperative temperature reaudit - the chilling issues. The Anesthesiology Annual Meeting. 2008. http://www.asaabstracts.com/strands/asaabstracts/abstr act.htm?year=2008\&index=15\&absnum=1930. Accessed $22 \mathrm{Mar} 2020$.

37. Scott AV, Stonemetz JL, Wasey JO, Johnson DJ, Rivers RJ, Koch CG, et al. Compliance with surgical care improvement project for body temperature management (SCIP Inf-10) is associated with improved clinical outcomes. Anesthesiology. 2015;123:116-25.

38. Bamgbade OA. Perioperative temperature management in day-case surgical patients. Eur J Anaesthesiol. 2012;29:354-5.

39. Yi J, Lei Y, Xu S, Si Y, Li S, Xia Z, et al. Intraoperative hypothermia and its clinical outcomes in patients undergoing general anesthesia: national study in China. PLoS One. 2017;12:e0177221.

40. Frank SM, El-Rahmany HK, Cattaneo CG, Barnes RA. Predictors of hypothermia during spinal anesthesia. Anesthesiology. 2000;92:1330-4. https://doi.org/10.1097/00000542-200005000-00022.

41. Cassey JG, King RAR, Armstrong P. Is there thermal benefit from preoperative warming in children? Paediatr Anaesth. 2010;20:63-71. https://doi. org/10.1111/j.1460-9592.2009.03204.x.

42. Frank SM, Beattie C, Christopherson R, Norris EJ, Rock P, Parker S, et al. Epidural versus general anesthesia, ambient operating room temperature, and patient age as predictors of inadvertent hypothermia. Anesthesiology. 1992;77:252-7.

43. Waeschle RM, Russo SG, Sliwa B, Bleeker F, Russo M, Bauer M, et al. Perioperative thermal management in Germany varies depending on the hospital size. Anaesthesist. 2015;64:612-22. https://doi.org/10.1007/ s00101-015-0057-z.

44. Weaver $L$, Beebe TJ, Rockwood T. The impact of survey mode on the response rate in a survey of the factors that influence Minnesota physicians' disclosure practices. BMC Med Res Methodol. 2019;19:73. https:// doi.org/10.1186/s12874-019-0719-7.

\section{Publisher's Note}

Springer Nature remains neutral with regard to jurisdictional claims in published maps and institutional affiliations.

\footnotetext{
Ready to submit your research? Choose BMC and benefit from:

- fast, convenient online submission

- thorough peer review by experienced researchers in your field

- rapid publication on acceptance

- support for research data, including large and complex data types

- gold Open Access which fosters wider collaboration and increased citations

- maximum visibility for your research: over 100M website views per year
}

At BMC, research is always in progress.

Learn more biomedcentral.com/submissions 